\title{
Correction to: Validation for the prevalence of virus complex and identification of virus resistance lines among the genotypes of chilli (Capsicum annuum L.)
}

\author{
Kaginalli Chandrashekarappa Megharaj ${ }^{1}$ Prabhudeva Shantappa Ajjappalavara ${ }^{2}$. \\ Hanamathagouda Bheemagouda Patil ${ }^{2} \cdot$ Mohammad Abdul Kareem $^{2}$. Shet Ratnakar ${ }^{2}$. \\ Satyanarayana Raghavendra ${ }^{2}$. Gopalkrishna Hegde ${ }^{3}$. Dalasanuru Chandregowda Manjunathagowda ${ }^{1,4}$ (D)
}

Published online: 5 July 2021

(c) Society for Plant Research 2021

\section{Correction to: Vegetos https://doi.org/10.1007/s42535-021-00224-y}

The original version of this article unfortunately contained a mistake. The spelling of Dalasanuru Chandregowda Manjunathagowda's name was incorrect. The corrected author list is given above. The original article has been corrected.

Publisher's Note Springer Nature remains neutral with regard to jurisdictional claims in published maps and institutional affiliations.

The original article can be found online at https://doi.org/10.1007/ s42535-021-00224-y.

Dalasanuru Chandregowda Manjunathagowda dc.manjunath@icar.gov.in

1 College of Horticulture, University of Horticultural Sciences, Bagalkot, Karnataka 587 104, India

2 Horticulture Research and Extension Station, University of Horticultural Sciences, Devihosur, Haveri, Karnataka 581 110, India

3 R\&D, Noble Seed Pvt Ltd, Bengaluru, Karnataka, India

4 ICAR-Directorate of Onion and Garlic Research, Rajgurunagar, Pune, Maharashtra 410505, India 